\title{
Diversity matters: opportunities in the study of the genetics of psychotic disorders in low- and middle-income countries in Latin America
}

\author{
Lais Fonseca, ${ }^{1,2}$ (iD Brena F. Sena, ${ }^{3,4}$ Nicolas Crossley, ${ }^{5,6}$ Carlos Lopez-Jaramillo, ${ }^{7,8}$ Karestan \\ Koenen, ${ }^{3,4}$ Nelson B. Freimer, ${ }^{9,10,11}$ Rodrigo A. Bressan, ${ }^{1,2}$ Sintia I. Belangero, ${ }^{1,12}$ Marcos L. \\ Santoro, ${ }^{1,12, *}$ Ary Gadelha ${ }^{1,2, *}$ iD \\ ${ }^{1}$ Laboratório Interdisciplinar de Neurociências Clínicas (LiNC), Universidade Federal de São Paulo (UNIFESP), São Paulo, SP, Brazil. ${ }^{2}$ Programa \\ de Esquizofrenia (PROESQ), Departamento de Psiquiatria, UNIFESP, São Paulo, SP, Brazil. ${ }^{3}$ Department of Epidemiology, Harvard T.H. Chan \\ School of Public Health, Boston, MA, USA. ${ }^{4}$ Stanley Center for Psychiatric Research, Broad Institute, Massachusetts Institute of Technology (MIT) \\ and Harvard, Cambridge, MA, USA. ${ }^{5}$ Department of Psychiatry, School of Medicine, Pontificia Universidad Católica de Chile, Santiago, Chile. \\ ${ }^{6}$ Department of Psychosis Studies, Institute of Psychiatry, Psychology and Neuroscience, King's College London, London, UK. ${ }^{7}$ Research Group \\ in Psychiatry, Department of Psychiatry, School of Medicine, Universidad de Antioquia, Medellin, Colombia. ${ }^{8}$ Mood Disorders Program, Hospital \\ San Vicente Fundación, Medellin, Colombia. ${ }^{9}$ Department of Psychiatry and Biobehavioral Sciences, University of California (UCLA), Los \\ Angeles, CA, USA. ${ }^{10}$ Center for Neurobehavioral Genetics, Semel Institute for Neuroscience and Human Behavior, UCLA, Los Angeles, CA, \\ USA. ${ }^{11}$ Department of Human Genetics, UCLA, Los Angeles, CA, USA. ${ }^{12}$ Disciplina de Genética, Departamento de Morfologia e Genética, \\ UNIFESP, São Paulo, SP, Brazil. * These authors have contributed equally to this manuscript.
}

\begin{abstract}
Lack of diversity regarding genetic and environmental backgrounds weakens the generalization and clinical applicability of research findings on psychotic disorders. Notably, Latin Americans have been generally neglected in genetic studies, comprising less than $2 \%$ of genome-wide association study samples. But Latin American populations represent a unique opportunity for research, given the exceptionally high ethnic admixture of this group. Increasing genetic diversity is essential to improve the fine mapping of known regions associated with psychotic disorders, discover novel genetic associations, and replicate studies. Additionally, Latin America is characterized by massive social, political, and economic inequalities, all known risk factors for mental health issues, including psychotic disorders. This article aims to 1) discuss the challenges and advantages of studying Latin America's particular genetic makeup and environmental context; 2) review previous studies conducted in the region; and 3) describe three Latin American research initiatives in progress: the Neuropsychiatric Genetics of Psychosis in Mexican Populations (NeuroMEX), the Paisa, and the Latin American Network for the Study of Early Psychosis (ANDES) studies.
\end{abstract}

Keywords: Latin America; psychotic disorders; schizophrenia; genetics; environment

\section{Introduction}

Psychotic spectrum disorders - mainly schizophrenia, schizoaffective, and bipolar disorder - have an estimated lifetime prevalence of around $3.5 \%{ }^{1}$ and represent a major global health burden, both at individual and public levels. ${ }^{2}$ Despite their social relevance, the pathophysiological pathways leading to psychotic disorders remain mostly uncertain. The development of research on the etiological features of psychosis is a crucial step towards more effective and improved diagnostic tools and treatments. To date, the most established hypothesis depicts psychotic disorders as a byproduct of gene-environment interactions during neurodevelopment. Thus, a broader view of genetic features and environmental exposures can provide new insights into the underlying neurobiology.

Correspondence: Ary Gadelha, Laboratório Interdisciplinar de Neurociências Clínicas, Universidade Federal de São Paulo, Rua Pedro de Toledo, 669, CEP 04039-032, São Paulo, SP, Brazil.

E-mail: aryararipe@gmail.com

Submitted Jun 15 2020, accepted Sep 22 2020, Epub Nov 232020.
Most genetic studies on psychosis, however, have been conducted in high-income countries, using essentially European descendants. ${ }^{3,4}$ This lack of ethnic diversity stands out for large-scale genome-wide association studies (GWAS) in general, as more than $78 \%$ of these samples are from European ancestry. ${ }^{5}$ Consequently, other groups remain widely underrepresented. Latin Americans comprise merely $1.3 \%$ of all GWAS samples, ${ }^{5}$ despite accounting for $8.4 \%$ of the world population, ${ }^{6}$ which leads not only to serious ethical qualms, but also to critical scientific repercussions, since the same GWAS findings may not be replicable across ethnic groups. ${ }^{7}$

This article highlights the importance of investigating the genetics of psychotic disorders in low- and middleincome countries (LMIC) from a Latin American perspective. We also discuss how this genetic background

How to cite this article: Fonseca L, Sena BF, Crossley N, LopezJaramillo C, Koenen K, Freimer NB, et al. Diversity matters: opportunities in the study of the genetics of psychotic disorders in low- and middle-income countries in Latin America. Braz J Psychiatry. 2021;43:631-637. http://dx.doi.org/10.1590/1516-4446-2020-1240 
interaction with the deprived setting of this region could benefit research. Finally, we review Latin America's participation in genetic studies so far and describe three ongoing projects related to psychotic disorders in Latin America.

\section{How genetic studies in Latin American populations can improve our understanding of psychotic disorders}

Latin America encompasses 20 countries and over 650 million citizens ${ }^{6}$ in a vast geographic region, each with its own heterogeneous demographic features. From the admixture point of view, Latin America provides a highly diversified genetic pool, stemming from Native American, European, African, and Asian ancestry components that resulted from unprecedented transcontinental migrations since the 15th century.

The distribution of these ancestries, however, is extremely heterogeneous across the continent. Populations from Mexico, Peru, Ecuador, and Bolivia present over $40 \%$ Native American ancestry, whereas those of Uruguay, Argentina, and southern Brazil have less than $10 \%$. Likewise, African ancestry is disproportionately encountered due to slavery and the colonial activities of European countries. Consequently, the African ancestry in Latin America ranges from Caribbean countries (mainly Haiti and Jamaica), which have major African contribution, to Argentina and Uruguay, for instance, whose populations have less than $5 \%$ African ancestry. ${ }^{8}$

A more in-depth look into African migration illustrates the complexity of ethnic diversity across the region, since its distributions also vary considerably within each country: in Brazil, for example, the population of Salvador (Northeast region) presents $50 \%$ African ancestry, the largest in the country, ${ }^{9}$ whereas Southern Brazil has an African ancestry lower than $10 \%$. These differences usually reflect the economic activities that motivated large, forced migrations. There are also ethnic differences within African ancestry, with greater West African ancestry in the Northeast of Brazil and East African ancestry in the Southeast region. ${ }^{9}$ In general, the same applies to European ancestry and migration flows from other continents.

One characteristic that usually distinguishes Latin Americans is their pronounced interethnic admixture. ${ }^{10-12}$ This contrasts with the genetic makeup of European populations, which limits the applicability of current genetic findings. Polygenic predictors of risk, namely the Polygenic Risk Score (PRS), represent a key instrument to approach complex disorders. PRS summarizes the genome-wide effects of thousands genetic variants for a specific trait and, in the last decade, have allowed substantial insights into complex illnesses. ${ }^{13-15}$ But these scores are mainly derived from European samples, and such reduced ethnic diversity weakens the translation of results to non-European populations. ${ }^{7,16}$ For instance, among admixed populations, particularly those enriched with African ancestry, PRS has shown prediction accuracies up to $75 \%$ lower than in Europeans. ${ }^{16,17}$
Studying more diverse samples would enhance the applicability of research findings. But, ultimately, a primary reason for including other populations is to obtain a representation of different allelic variants and, above all, allele frequencies different from those encountered in European samples. In fact, the inclusion of non-European subjects has shown to increase the number of identified genomic associations and aid in the fine-mapping of GWAS loci. ${ }^{18}$ The few studies that did include nonEuropean populations discovered variants associated with a wide range of phenotypes. ${ }^{19-22}$ The 1000 Genomes (1000G) Project Consortium ${ }^{23}$ found that, in general, individuals from African populations present 800,000 more variant sites than European and Asian populations. ${ }^{23}$ Likewise, studies have shown that admixed populations with African ancestry presented the greatest variability per individual regarding the number of variants (for example, Colombians and Puerto Ricans from 1000G). As such, this increased number of variants naturally contributes to the identification of new genomic associations: although African populations represent $2.4 \%$ of GWAS samples, they were responsible for $7 \%$ of all associations discovered; similarly, despite only accounting for $1.3 \%$ of GWAS samples, studies of Latin American populations have identified $4 \%$ of all associations. ${ }^{24}$

Notwithstanding the clear advantages of increasing diversity, admixed subjects are consistently removed from GWAS, mainly because population substructure can bias results, ${ }^{25-29}$ even after global ancestry or principal component adjustments. ${ }^{30}$ However, new tools and statistical methods developed in the last few years to approach ancestry more effectively, such as Tractor $^{31}$ and asaMap, ${ }^{32}$ should encourage the inclusion of admixed populations in large genomic studies.

\section{How the study of the Latin American environment can improve our understanding of psychotic disorders}

While the genetic contribution to psychosis is well-established, it does not fully explain the overall risk for these conditions. Genetic risk can be a potential catalyst for the independent effects of pathogenic environmental exposures and vice versa.

Some environmental risk factors for psychotic disorders seem to be particularly frequent and intense in Latin America, i.e., violence, poverty, and urbanicity. According to the United Nations International Children's Emergency Fund (UNICEF), ${ }^{33}$ the overall wealth inequality in Latin American countries is the highest in the world and is directly linked to increased poverty,$^{34}$ unregulated urbanization, ${ }^{35}$ crime, violence, ${ }^{36,37}$ and limited social or healthcare assistance. ${ }^{38} \mathrm{~A}$ recent report ${ }^{36}$ showed that, outside war zones, 43 of the world's 50 most dangerous cities are located in Latin America, with one-third of the world's homicides in 2018 occurring in this region. Latin America also has the world's highest rates of interpersonal violence and kidnapping. ${ }^{37}$ Consequently, social inequality provides a natural experiment in which impoverished communities that are highly exposed to violence coexist within the same 
cities (or, frequently, within the same neighborhoods) as wealthy and privileged populations.

Environmental exposures are thought to be driven by social relationships and modulated by economic, health, and educational opportunities. Thus, studying psychotic disorders across different settings would provide a more comprehensive perspective, especially if approached through syndemics. The syndemic model ${ }^{39}$ was designed to look at multifactorial health conditions that interact adversely in a determined population, accounting for the contextual and social aspects that could increase their occurrence. Biosocial factors are understood to operate intertwined at various levels, with a greater cumulative effect than each factor individually, which confirms the existence of a converging synergic relationship. Consequently, these conditions "are most likely to emerge under conditions of health inequality caused by poverty, stigmatization, stress or structural violence."39

Researchers must keep in mind that instruments developed to assess environmental exposures in high-income countries may be somewhat incompatible and inconsistent to measure stressful life events and their possible effects comparatively, for example, in contexts of high violence and deprivation. $^{40-42}$ The World Health Organization (WHO) Survey Consortium ${ }^{37,43}$ investigated a large population sample from 24 countries across six continents and found that the rate and type of trauma exposure varied considerably among nations, with Latin Americans presenting the highest overall rates. Unexpectedly, the prevalence of posttraumatic stress disorder in high-income countries was similar or even higher than that in LMIC, which could be a result of cross-population variability in specific psychometric instruments. On the other hand, these findings could also reflect resilience traits, with possible genetic associations and/or environmentally acquired mechanisms, which suggests that Latin American populations may be desensitized to trauma exposure.

However, it is unclear how psychosis incidence rates, disease severity, or age of onset could be impacted differently by Latin America's adverse environment compared to high-income countries, indicating further opportunities to study gene-environment interaction. One possible approach to handling this myriad of effects is through recently described poly-environmental risk scores, ${ }^{44,45}$ which, analogous to the PRS (although more dynamic), could load multiple environmental risk factors and express the impact of cumulative exposure, which is also in line with the syndemic framework. Additionally, the relative weights of each risk factor can be calculated for different regions and aggregate scores (as opposed to individual risks) and can be used to compare the overall environmental risk for psychosis. Like the previously discussed genetic findings, investigating environmental exposures in different regions could reveal new, previously undescribed risk factors and contribute to the development of more accurate, reproducible measures.

\section{Previous Latin American research}

Before genome-wide investigations, candidate gene studies with a case-control design were the main approach to exploring associations between single genomic loci and psychotic disorders. Even though the results have been, in general, mostly non-replicable, ${ }^{46}$ innumerous genes and variants have been tested, resulting in the identification of some small effect alleles.

Recently, Liu et al. ${ }^{47}$ conducted an extensive systematic review of schizophrenia candidate gene studies, which investigated a total of 20,570 single nucleotide polymorphisms (SNPs) in more than 3,414 genes. The authors made all the results available, which comprised the raw data of every study, including the country of origin and ethnicity of each sample. Among the 1,188 eligible publications, only 19 were from Latin America, which represents $1.5 \%$ of the included reports: Brazil (13 studies $^{48-59}$ ), Mexico (four studies ${ }^{60-63}$ ), and Costa Rica (two studies ${ }^{64,65}$, although the samples overlapped considerably. Overall, the 19 studies assessed seven cohorts, all with relatively small sample sizes, totaling 1,426 cases (range $=69-421$; standard deviation $[S D]=120.1$ ) and 2,020 controls (range $=85-834 ; S D=298.0$ ), whose ethnicities were described as "Mixed."

Other Latin American studies have gathered samples larger than 1,000 subjects and performed candidate loci/ gene associations. Gonzalez et al. ${ }^{66}$ evaluated 91 SNPs previously associated with schizophrenia or bipolar disorder in a Latin American cohort of 2,254 individuals (706 cases of bipolar disorder or schizoaffective disorder and 1,548 probands) and were able to replicate the association of eight SNPs. We found that $80 \%$ of these studies aimed at replicating the findings of other populations, rather than investigating new genetic associations.

To date, Bigdeli et al. ${ }^{22}$ have conducted the only Latin American GWAS with reasonable power, which included 4,324 individuals (1,234 cases). This study identified a novel genome-wide significant association within the GALNT13 gene in the Latino cohort alone and 101 loci when metaanalyzing it with the Schizophrenia Working Group of the Psychiatric Genomics Consortium (PGC-Schizophrenia), ${ }^{4}$ eight of which had not been previously associated with schizophrenia. Moreover, Bigdeli et al. showed that metaanalyzing combined data from European (PGC-Schizophrenia) admixed African and Latinos improved the fine-mapping of nine regions and increased PRS prediction for Latinos from 1.7 to $2.1 \%$ (measured by liability $R^{2}$ ).

Recent technologies have allowed the scanning of the entire exome, allowing the identification of rare genetic variants, which could lead to larger effects in deleterious phenotypes than common variants. Moreover, wholeexome sequencing investigates variants that are not captured by SNP genotyping arrays. Wu et al. ${ }^{67,68}$ performed a systematic review of genetic research on schizophrenia and set up an open database (http://www.szdb.org) containing all of the identified findings from exome sequencing publications from inception to May 2020. Of the 16 studies, 15 evaluated essentially Caucasian samples and one assessed Asian subjects. Although none of the studies were conducted in Latin America, two were performed in the United States and included Latino samples, representing $6^{69}$ and $1 \%{ }^{70}$ of all subjects.

Altogether, this comprehensive review demonstrates that few genetic studies with large samples have been 
carried out in Latin America, which, consequently, hinders our understanding of ethnic diversity and allele frequency in psychotic disorders. As such, international collaborations within Latin America represent a possible solution for these issues.

\section{Description of ongoing projects and the results so far}

Finally, in addition to published papers, we searched among leading regional schizophrenia researchers for current initiatives aimed at building large and thoroughly assessed cohorts to change this scenario. The Neuropsychiatric Genetics of Psychosis in Mexican Populations (NeuroMEX), Paisa, and Latin American Network for the Study of Early Psychosis (ANDES) projects are the result of international collaborations between Latin America and high-income nations. These international consortia could be used as framework in the future, possibly encouraging further actions (additional information for each of the following studies can be found in Box 1, available as online-only supplementary material).

\section{The NeuroMEX Study}

NeuroMEX is a three-part collaboration between the Harvard T.H. Chan School of Public Health, the Stanley Center for Psychiatric Genetics at the Broad Institute of Massachusetts Institute of Technology and Harvard, and the National Institute of Psychiatry Ramón de la Fuente Muñiz (INPRFM) in Mexico City. The NeuroMEX Study aims to recruit a total of 8,000 participants throughout Mexico, including 4,000 psychosis cases and 4,000 controls in a large GWAS, combined with extensive phenotypic data related to psychosis, schizophrenia, and bipolar disorder. The study seeks to build capacity and train Mexican collaborators to ensure the advancement of neuropsychiatric genetics research in Mexico.

\section{Paisa Study}

Paisa encompasses several administrative regions in Colombia, including the departments of Antioquia, Caldas, Risaralda and Quindío. ${ }^{71,72}$ The largest cities in this region are Medellin, Manizales, and Pereira, and the whole area includes a population of approximately 9 million individuals. The Paisa population, which originated between the 15th and 19th century, primarily from the genetic admixture of Native American women and European men is considered a genetic isolate. ${ }^{73-75}$ The isolation provided by the Andes Mountains, the rapid demographic growth of 25 generations and the subsequent population bottleneck that occurred during the initial admixture resulted in patterns of allelic variation that differ considerably from neighboring populations. ${ }^{73,76}$ Parental ancestry analyses of this population have shown that the $Y$ chromosome lineage consists of 94\% European, 5\% African, and 1\% Native American; the mitochondrial DNA lineage is $90 \%$ Native American, $8 \%$ African, and $2 \%$ European. The reduced diversity of surnames introduced by the founders ${ }^{71}$ allows easily traceable genealogical antecedents. There is also an increased prevalence of autosomal recessive disorders in the region associated with high degrees of consanguinity. ${ }^{71}$ Such unique features make the Paisa population especially valuable for the study of rare variant associations.

Previous genetic investigations in the Paisa population have contributed to our understanding of several neuropsychiatric disorders: Alzheimer's disease, ${ }^{77,78}$ attention deficit hyperactivity disorder, ${ }^{79}$ bipolar disorder, ${ }^{80-84}$ and schizophrenia. ${ }^{76}$ More recently, the University of California, Los Angeles and the Universidad de Antioquia in Colombia initiated a case control study in the Paisa region to evaluate the relationship between severe mental illness phenotypes and genetic variants that may contribute to disease risk and development. For this study, a cohort of 8,000 individuals with diagnoses of mood or psychotic disorders (bipolar disorder, major depression disorder and schizophrenia) and 2,000 healthy controls from the Paisa region are being recruited and systematically evaluated with extensive clinical and cognitive batteries, as well as with genome wide genomic analyses.

\section{ANDES Study}

ANDES is a consortium created in 2018 of 15 different groups from six Latin American countries: Argentina, Brazil, Bolivia, Chile, Colombia, and Mexico. Its main objective is to stimulate research collaborations within the region, aiming to capitalize on existing resources, facilitate knowledge transfer across groups, and focus on specific aspects of psychosis in these countries. ${ }^{85}$ In addition to genetic studies, the participating groups are also conducting clinical, cognitive, epidemiological, economic, and neuroimaging analyses. As a first step, though, the network has focused on harmonizing existing data.

To illustrate this point, a recent study included structural MRI images from 334 patients with schizophrenia and 262 controls and was able to examine the modulating effect of poverty and violence on the brain in the harsh Latin American environment. ${ }^{86}$ Currently, projects are analyzing previously acquired genetic data to examine the validity of PRS for Latin American populations.

\section{Discussion}

Although schizophrenia has a high heritability (around $80 \%$ based on twin studies ${ }^{87}$ ), the largest available GWAS explained only one-quarter of the disease variance, ${ }^{88}$ reinforcing the need to explore additional genetic and environmental variants. But to conduct such investigations, it is imperative to increase the diversity of research populations.

Latin America can contribute to both, given the admixed genetics of Latin Americans and their intense setting. However, researchers must face tough challenges, particularly the scarcity of research funding in the region, which calls for strategies to promote innovative studies. A syndemic framework could benefit new data collection efforts by maximizing results and reducing costs, for example, through the assessment of correlated phenotypes, such as 
trauma, psychosis, and cardiovascular diseases, all enhanced by each other and the environment. Additionally, as we suggested, employing weighted poly-environmental risk scores across different socioeconomic contexts might provide some insight into its overall effect on psychotic disorders and how adverse exposures possibly catalyze genetic liability.

Regarding genetic investigations specifically, public datasets and mobile applications will become increasingly important tools to achieve deeper and cheaper phenotyping. But, again, the lack of financial support to develop this capacity results in problematic bottlenecks. In Colombia, for example, the PAISA project has been largely facilitated by the availability of nationwide electronic records, which are unfortunately not common across Latin America. Furthermore, the planned quick collection of large genetic samples should be paralleled with efforts to improve exposome phenotyping. ${ }^{89}$

The ongoing projects described herein represent critical initiatives to foster Latin America's role in international research. The NeuroMEX and Paisa projects show how partnerships with high-income countries can accelerate processes and should be stimulated. Likewise, the ANDES network provides an example of how collaborations even among Latin American countries could increase samples and optimize resources.

In conclusion, Latin American countries share many characteristics, including poverty, economic inequality, and violence, but also differ substantially in terms of culture, language, and genetic backgrounds. As such, these countries work as a natural laboratory to understand pathways connecting genetic liability and environmental exposures in the trajectories of psychotic disorders and could help increase the ethnic diversity of the research. However, the continuing lack of funding support and overall encouragement of research represent a great challenge. Extensive funding and partnerships are, therefore, required not only to collect data, but also to build the capacity that will allow future research initiatives.

\section{Acknowledgements}

This study was financed in part by Coordenação de Aperfeiçoamento Pessoal de Nível Superior (CAPES; Finance Code 001). RAB has received grants from the following governmental research funding agencies: CAPES, Conselho Nacional de Desenvolvimento Científico e Tecnológico (CNPq), and Fundação de Amparo à Pesquisa do Estado de São Paulo (FAPESP; 2016/ 022465 and 2011/50740-5).

\section{Disclosure}

$R A B$ has received research grants from Janssen Cilag, Novartis, and Roche; he has been a forum consultant for Janssen, Novartis, and Roche; and has participated in speaker bureaus for Ache, Janssen, Lundbeck, and Novartis. AG has been a consultant and/or advisor to or has received honoraria from: Aché, Daiichi-Sankyo, Torrent, Bayer, Cristalia, Daiichi-Sankyo, and Janssen. The other authors report no conflicts of interest.

\section{References}

1 Perälä J, Suvisaari J, Saarni SI, Kuoppasalmi K, Isometsä E, Pirkola $\mathrm{S}$, et al. Lifetime prevalence of psychotic and bipolar I disorders in a general population. Arch Gen Psychiatry. 2007;64:19-28.

2 Knapp M, Mangalore R, Simon J. The global costs of schizophrenia. Schizophr Bull. 2004;30:279-93.

3 Demontis D, Walters RK, Martin J, Mattheisen M, Als TD, Agerbo E, et al. Discovery of the first genome-wide significant risk loci for attention deficit/hyperactivity disorder. Nat Genet. 2019;51:63-75.

4 Schizophrenia Working Group of the Psychiatric Genomics Consortium. Biological insights from 108 schizophrenia-associated genetic loci. Nature. 2014;511:421-7.

5 Sirugo G, Williams SM, Tishkoff SA. The missing diversity in human genetic studies. Cell. 2019;177:26-31.

6 United Nations (UN), Department of Economic and Social Affairs Population Division. Overall total population. World population prospects 2019 [Internet]. 2019 [cited 10 Sep 2020]. https://population. un.org/wpp/

7 Cavazos T, Witte J. Inclusion of variants discovered from diverse populations improves polygenic risk score transferability. bioRxiv. 2020;108845. doi: https://doi.org/10.1101/2020.05.21.108845

8 23andMe. Research team [Internet]. 2020 [cited 2020 Jan 14]. research.23andme.com/research/

9 Kehdy FS, Gouveia MH, Machado M, Magalhães WC, Horimoto AR, Horta BL, et al. Origin and dynamics of admixture in Brazilians and its effect on the pattern of deleterious mutations. Proc Natl Acad Sci. 2015;112:8696-701.

10 Norris ET, Wang L, Conley AB, Rishishwar L, Mariño-Ramírez L, Valderrama-Aguirre A, et al. Genetic ancestry, admixture and health determinants in Latin America. BMC Genomics. 2018;19:861.

11 Wang S, Ray N, Rojas W, Parra MV, Bedoya G, Gallo C, et al. Geographic patterns of genome admixture in Latin American Mestizos. PLoS Genet. 2008;4:e1000037.

12 Ruiz-Linares A, Adhikari K, Acuña-Alonzo V, Quinto-Sanchez M, Jaramillo C, Arias W, et al. Admixture in Latin America: geographic structure, phenotypic diversity and self-perception of ancestry based on 7,342 individuals. PLoS Genet. 2014;10:e1004572.

13 Maas P, Barrdahl M, Joshi AD, Auer PL, Gaudet MM, Milne RL, et al. Breast cancer risk from modifiable and nonmodifiable risk factors among white women in the United States. JAMA Oncol. 2016;2: 1295-302.

14 Schumacher FR, Al Olama AA, Berndt SI, Benlloch S, Ahmed M, Saunders EJ, et al. Association analyses of more than 140,000 men identify 63 new prostate cancer susceptibility loci. Nat Genet. 2018;50:928-36.

15 Sharp SA, Rich SS, Wood AR, Jones SE, Beaumont RN, Harrison JW, et al. Development and standardization of an improved type 1 diabetes genetic risk score for use in newborn screening and incident diagnosis. Diabetes Care. 2019;42:200-7.

16 Martin AR, Gignoux CR, Walters RK, Wojcik GL, Neale BM, Gravel S, et al. Human demographic history impacts genetic risk prediction across diverse populations. Am J Hum Genet. 2017; 100:635-49.

17 Vassos E, Di Forti M, Coleman J, Iyegbe C, Prata D, Euesden J, et al. An examination of polygenic score risk prediction in individuals with first-episode psychosis. Biol Psychiatry. 2017;81:470-7.

18 Li YR, Keating BJ. Trans-ethnic genome-wide association studies: advantages and challenges of mapping in diverse populations. Genome Med. 2014;6:91.

19 SIGMA Type 2 Diabetes Consortium;Estrada K, Aukrust I, Bjørkhaug $\mathrm{L}$, Burtt NP, Mercader JM, et al. Association of a low-frequency variant in HNF1A with type 2 diabetes in a Latino Population. JAMA. 2014;311:2305-14.

20 SIGMA Type 2 Diabetes Consortium;Williams AL, Jacobs SB, Moreno-Macías H, Huerta-Chagoya A, Churchhouse C, et al. Sequence variants in SLC16A11 are a common risk factor for type 2 diabetes in Mexico. Nature. 2014;506:97-101.

21 Peterson RE, Kuchenbaecker K, Walters RK, Chen CY, Popejoy AB, Periyasamy S, et al. Genome-wide association studies in ancestrally diverse populations: opportunities, methods, pitfalls, and recommendations. Cell. 2019;179:589-603.

22 Bigdeli TB, Genovese G, Georgakopoulos P, Meyers JL, Peterson $\mathrm{RE}$, lyegbe $\mathrm{CO}$, et al. Contributions of common genetic variants to 
risk of schizophrenia among individuals of African and Latino ancestry. Mol Psychiatry. 2020;25:2455-67.

231000 Genomes Project Consortium; Auton A, Brooks LD, Durbin RM, Garrison EP, Kang HM, et al. A global reference for human genetic variation. Nature. 2015;526:68-74.

24 Morales J, Welter D, Bowler EH, Cerezo M, Harris LW, McMahon AC, et al. A standardized framework for representation of ancestry data in genomics studies, with application to the NHGRI-EBI GWAS catalog. Genome Biol. 2018;19:21.

25 Huang H, Peloso G, Howrigan D, Rakitsch B, Simon-Gabriel CJ, Goldstein J, et al. Bootstrat: population informed bootstrapping for rare variant tests. bioRxiv. 2016;068999. doi: https://doi.org/10.1101/ 068999

26 Sul JH, Martin LS, Eskin E. Population structure in genetic studies: confounding factors and mixed models. PLOS Genet. 2018;14: e1007309.

27 Sohail M, Maier RM, Ganna A, Bloemendal A, Martin AR, Turchin $\mathrm{MC}$, et al. Polygenic adaptation on height is overestimated due to uncorrected stratification in genome-wide association studies. Elife. 2019;8:e39702.

28 Coram MA, Fang H, Candille SI, Assimes TL, Tang H. Leveraging multi-ethnic evidence for risk assessment of quantitative traits in minority populations. Am J Hum Genet. 2017;101:218-26.

29 Martin ER, Tunc I, Liu Z, Slifer SH, Beecham AH, Beecham GW. Properties of global- and local-ancestry adjustments in genetic association tests in admixed populations. Genet Epidemiol. 2018, 42:214-29.

30 Price AL, Patterson NJ, Plenge RM, Weinblatt ME, Shadick NA Reich D. Principal components analysis corrects for stratification in genome-wide association studies. Nat Genet. 2006;38:904-9.

31 Atkinson E, Maihofer A, Kanai M, Martin A, Karczewski K, Santoro M, et al. Tractor: a framework allowing for improved inclusion of admixed individuals in large-scale association studies. bioRxiv. 2020;100727. doi: https://doi.org/10.1101/2020.05.17.100727

32 Skotte L, Jørsboe E, Korneliussen TS, Moltke I, Albrechtsen A. Ancestry-specific association mapping in admixed populations. Genet Epidemiol. 2019;43:506-21.

33 Ortiz I, Cummins M. Global inequality: beyond the bottom billion -- a rapid review of income distribution in 141 countries. SSRN. 2012;180 5046. https://dx.doi.org/10.2139/ssrn.1805046

34 Economic Commission for Latin america and the Caribbean (ECLAC). Social Panorama of Latin America. 2019 [Internet]. 2019 Dec [cited 2020 Oct 1]. repositorio.cepal.org/bitstream/handle/11362/ 44989/1/S1901132 en.pdf

35 United Nations (UN), Department of Economic and Social Affairs. 2018 revision of world urbanization prospects [Internet]. 2018 May 16 [cited 2020 Oct 1]. www.un.org/development/desa/publications/2018revision-of-world-urbanization-prospects.html

36 Muggah R, Aguirre KA. Citizen security in Latin America: facts and figures. Vol. 33. Rio de Janeiro: Instituto Igarapé; 2018.

37 Benjet C, Bromet E, Karam EG, Kessler RC, McLaughlin KA, Ruscio $\mathrm{AM}$, et al. The epidemiology of traumatic event exposure worldwide: results from the world mental health survey consortium. Psychol Med. 2016;46:327-43.

38 Fay M, World Bank Group. The urban poor in Latin America [Internet]. Washington: The International Bank for Reconstruction and Development/The World Bank. 2005 [cited 2020 Oct 1]. https:// openknowledge.worldbank.org/handle/10986/7263

39 Singer M, Bulled N, Ostrach B, Mendenhall E. Syndemics and the biosocial conception of health. Lancet. 2017;389:941-50.

40 Marsella A, Wong PTP, Wong LCJ, Kim U, Yang KS, Hwang KK, et al. Cross-cultural assessment of psychological trauma and PTSD. New York: Springer Science + Business Media; 2007.

41 Kisely S, Alichniewicz KK, Black EB, Siskind D, Spurling G, Toombs $M$. The prevalence of depression and anxiety disorders in indigenous people of the Americas: a systematic review and meta-analysis. J Psychiatr Res. 2017;84:137-52.

42 Guinart D, Kane JM, Correll CU. Is transcultural psychiatry possible? JAMA. 2019 Nov 14. doi: http://10.1001/jama.2019.17331. Online ahead of print

43 Kessler RC, Aguilar-Gaxiola S, Alonso J, Benjet C, Bromet EJ, Cardoso G, et al. Trauma and PTSD in the WHO world mental health surveys. Eur J Psychotraumatol. 2017;8:1353383.
44 Padmanabhan JL, Shah JL, Tandon N, Keshavan MS. The "polyenviromic risk score": aggregating environmental risk factors predicts conversion to psychosis in familial high-risk subjects. Schizophr Res. 2017;181:17-22.

45 Vassos E, Sham P, Kempton M, Trotta A, Stilo SA, Gayer-Anderson $\mathrm{C}$, et al. The Maudsley environmental risk score for psychosis. Psychol Med. 2020;50:2213-20.

46 Gejman PV, Sanders AR, Kendler KS. Genetics of schizophrenia: new findings and challenges. Annu Rev Genomics Hum Genet. 2011;12:121-44.

47 Liu C, Kanazawa T, Tian Y, Saini SM, Mancuso S, Mostaid MS, et al. The schizophrenia genetics knowledgebase: a comprehensive update of findings from candidate gene studies. Transl Psychiatry. 2019; 9:205.

48 Cordeiro Q, Talkowski ME, Chowdari KV, Wood J, Nimgaonkar V, Vallada $\mathrm{H}$. Association and linkage analysis of RGS4 polymorphisms with schizophrenia and bipolar disorder in Brazil. Genes Brain Behav. 2005;4:45-50.

49 Cordeiro Q, Siqueira-Roberto J, Zung S, Vallada H. Association between the DRD2-141C insertion/deletion polymorphism and schizophrenia. Arq Neuropsiquiatr. 2009;67:191-4

50 Ruano D, Macedo A, Soares MJ, Valente J, Azevedo MH, Hutz MH, et al. Transthyretin: no association between serum levels or gene variants and schizophrenia. J Psychiatr Res. 2007;41:667-72.

51 Ruano D, Aulchenko YS, Macedo A, Soares MJ, Valente J, Azevedo $\mathrm{MH}$, et al. Association of the gene encoding neurogranin with schizophrenia in males. J Psychiatr Res. 2008;42:125-33.

52 Cordeiro $\mathrm{Q}$, Siqueira-Roberto J, Vallada $\mathrm{H}$. Association between the SLC6A3 A1343G polymorphism and schizophrenia. Arq Neuropsiquiatr. 2010;68:716-9.

53 Cordeiro Q, da Silva RT, Vallada H. Association study between the rs165599 catechol-O-methyltransferase genetic polymorphism and schizophrenia in a Brazilian sample. Arq Neuropsiquiatr. 2012; 70:913-6.

54 Correa H, De Marco L, Boson W, Nicolato R, Teixeira AL, Campo VR et al. Association study of T102C 5-HT(2A) polymorphism in schizophrenic patients: diagnosis, psychopathology, and suicidal behavior. Dialogues Clin Neurosci. 2007;9:97-101.

55 Gouvêa ES, Santos Filho AF, Ota VK, Mrad V, Gadelha A, Bressan $\mathrm{RA}$, et al. The role of the CNR1 gene in schizophrenia: a systematic review including unpublished data. Braz J Psychiatry. 2017;39:160-71.

56 Junqueira R, Cordeiro Q, Meira-Lima I, Gattaz WF, Vallada H. Allelic association analysis of phospholipase A2 genes with schizophrenia. Psychiatr Genet. 2004;14:157-60.

57 Loch AA, van de Bilt MT, Bio DS, do Prado CM, de Sousa RT, Valiengo LL, et al. Epistasis between COMT Val158Met and DRD3 Ser9Gly polymorphisms and cognitive function in schizophrenia: genetic influence on dopamine transmission. Braz J Psychiatry. 2015;37:235-41

58 Meira-Lima I V, Pereira AC, Mota GF, Floriano M, Araújo F, Mansur $\mathrm{AJ}$, et al. Analysis of a polymorphism in the promoter region of the tumor necrosis factor alpha gene in schizophrenia and bipolar disorder: further support for an association with schizophrenia. Mol Psychiatry. 2003;8:718-20.

59 Ota VK, Bellucco FT, Gadelha A, Santoro ML, Noto C, Christofolin $\mathrm{DM}$, et al. PRODH polymorphisms, cortical volumes and thickness in schizophrenia. PLoS One. 2014;9:e87686.

60 Aguirre AJ, Apiquián R, Fresán A, Cruz-Fuentes C. Association analysis of exon III and exon I polymorphisms of the dopamine D4 receptor locus in Mexican psychotic patients. Psychiatry Res. 2007; 153:209-15.

61 Camarena B, Fresán A, Aguilar A, Escamilla R, Saracco R, Palacios $\mathrm{J}$, et al. Monoamine oxidase a and $\mathrm{B}$ gene polymorphisms and negative and positive symptoms in schizophrenia. ISRN Psychiatry. 2012;2012:852949.

62 García-Miss M del R, Pérez-Mutul J, López-Canul B, Solís-Rodríguez F, Puga-Machado L, Oxté-Cabrera A, et al. Folate, homocysteine, interleukin-6, and tumor necrosis factor alfa levels, but not the methylenetetrahydrofolate reductase $\mathrm{C677T}$ polymorphism, are risk factors for schizophrenia. J Psychiatr Res. 2010;44:441-6.

63 Tovilla-Zárate C, Medellín BC, Fresán A, López-Narváez L, Castro TB, Rojop IR, et al. No association between catechol-o-methyltransferase Val108/158Met polymorphism and schizophrenia or its 
clinical symptomatology in a Mexican population. Mol Biol Rep. 2013;40:2053-8.

64 Guella I, Sequeira A, Rollins B, Morgan L, Myers RM, Watson SJ, et al. Evidence of allelic imbalance in the schizophrenia susceptibility gene ZNF804A in human dorsolateral prefrontal cortex. Schizophr Res. 2014;152:111-6.

65 Moon E, Rollins B, Mesén A, Sequeira A, Myers RM, Akil H, et al. Lack of association to a NRG1 missense polymorphism in schizophrenia or bipolar disorder in a Costa Rican population. Schizophr Res. 2011;131:52-7.

66 Gonzalez S, Gupta J, Villa E, Mallawaarachchi I, Rodriguez M, Ramirez M, et al. Replication of genome-wide association study (GWAS) susceptibility loci in a Latino bipolar disorder cohort. Bipolar Disord. 2016;18:520-7.

$67 \mathrm{Wu}$ Y, Yao YG, Luo XJ. SZDB: a database for schizophrenia genetic research. Schizophr Bull. 2017;43:459-71.

$68 \mathrm{Wu}$ Y, Li X, Liu J, Luo XJ, Yao YG. SZDB2.0: an updated comprehensive resource for schizophrenia research. Hum Genet. 2020; 139:1285-97.

69 Gulsuner S, Walsh T, Watts AC, Lee MK, Thornton AM, Casadei S, et al. Spatial and temporal mapping of de novo mutations in schizophrenia to a fetal prefrontal cortical network. Cell. 2013;154: 518-29.

70 Need AC, McEvoy JP, Gennarelli M, Heinzen EL, Ge D, Maia JM, et al. Exome sequencing followed by large-scale genotyping suggests a limited role for moderately rare risk factors of strong effect in schizophrenia. Am J Hum Genet. 2012;91:303-12.

71 Bedoya G, Montoya P, Garcia J, Soto I, Bourgeois S, Carvajal L, et al. Admixture dynamics in Hispanics: a shift in the nuclear genetic ancestry of a South American population isolate. Proc Natl Acad Sci. 2006;103:7234-9.

72 Service S, DeYoung J, Karayiorgou M, Roos JL, Pretorious H, Bedoya $\mathrm{G}$, et al. Magnitude and distribution of linkage disequilibrium in population isolates and implications for genome-wide association studies. Nat Genet. 2006;38:556-60.

73 Jordan IK. The Columbian exchange as a source of adaptive introgression in human populations. Biol Direct. 2016;11:17.

74 Carvajal-Carmona LG, Soto ID, Pineda N, Ortíz-Barrientos D, Duque $\mathrm{C}$, Ospina-Duque $\mathrm{J}$, et al. Strong Amerind/white sex bias and a possible sephardic contribution among the founders of a population in northwest Colombia. Am J Hum Genet. 2000;67:1287-95.

75 Carvajal-Carmona LG, Ophoff R, Service S, Hartiala J, Molina J, Leon P, et al. Genetic demography of Antioquia (Colombia) and the Central Valley of Costa Rica. Hum Genet. 2003;112:534-41.

76 Arcos-Burgos M, Muenke M. Genetics of population isolates. Clin Genet. 2002;61:233-47.

77 Acosta-Baena N, Sepulveda-Falla D, Lopera-Gómez CM, JaramilloElorza MC, Moreno S, Aguirre-Acevedo DC, et al. Pre-dementia clinical stages in presenilin 1 E280A familial early-onset Alzheimer's disease: a retrospective cohort study. Lancet Neurol. 2011;10: 213-20.
78 Arboleda-Velasquez JF, Lopera F, O'Hare M, Delgado-Tirado S, Marino C, Chmielewska N, et al. Resistance to autosomal dominant Alzheimer's disease in an APOE3 Christchurch homozygote: a case report. Nat Med. 2019;25:1680-3.

79 Arcos-Burgos M, Jain M, Acosta MT, Shively S, Stanescu H, Wallis $\mathrm{D}$, et al. A common variant of the latrophilin 3 gene, LPHN3, confers susceptibility to ADHD and predicts effectiveness of stimulant medication. Mol Psychiatry. 2010;15:1053-66.

80 Kremeyer B, García J, Müller H, Burley MW, Herzberg I, Parra MV, et al. Genome-wide linkage scan of bipolar disorder in a Colombian population isolate replicates Loci on chromosomes 7p21-22, 1p31, $16 \mathrm{p} 12$ and 21q21-22 and identifies a novel locus on chromosome 12q. Hum Hered. 2010;70:255-68.

81 Peterson CB, Service SK, Jasinska AJ, Gao F, Zelaya I, Teshiba TM, et al. Characterization of expression quantitative trait Loci in pedigrees from Colombia and Costa Rica ascertained for bipolar disorder. PLOS Genet. 2016;12:e1006046.

82 Pagani L, St Clair PA, Teshiba TM, Service SK, Fears SC, Araya C, et al. Genetic contributions to circadian activity rhythm and sleep pattern phenotypes in pedigrees segregating for severe bipolar disorder. Proc Natl Acad Sci. 2016;113:E754-61.

83 Fears SC, Service SK, Kremeyer B, Araya C, Araya X, Bejarano J, et al. Multisystem component phenotypes of bipolar disorder for genetic investigations of extended pedigrees. JAMA Psychiatry. 2014;71:375-87.

84 Fears SC, Schür R, Sjouwerman R, Service SK, Araya C, Araya X, et al. Brain structure-function associations in multi-generational families genetically enriched for bipolar disorder. Brain. 2015;138: 2087-102.

85 Crossley NA, Alliende LM, Ossandon T, Castañeda CP, GonzálezValderrama A, Undurraga J, et al. Imaging social and environmental factors as modulators of brain dysfunction: time to focus on developing non-western societies. Biol Psychiatry Cogn Neurosci Neuroimaging. 2019;4:8-15.

86 Crossley N, Zugman A, Reyes-Madrigal F, Czepielewski LS, Castro MN, Diaz-Zuluaga A, et al. Structural brain abnormalities in schizophrenia in adverse environments: examining the effect of poverty and violence in six Latin American cities. Br J Psychiatry; 2020 Aug 18;1-7. doi: http://10.1192/bjp.2020.143. Online ahead of print

87 Sullivan PF, Kendler KS, Neale MC. Schizophrenia as a complex trait: evidence from a meta-analysis of twin studies. Arch Gen Psychiatry. 2003;60:1187-92.

88 Lee SH, DeCandia TR, Ripke S, Yang J. Schizophrenia Psychiatric Genome-Wide Association Study Consortium (PGC-SCZ); International Schizophrenia Consortium (ISC); et al. Estimating the proportion of variation in susceptibility to schizophrenia captured by common SNPs. Nat Genet. 2012;44:247-50.

89 Wild CP. Complementing the genome with an "exposome": the outstanding challenge of environmental exposure measurement in molecular epidemiology. Cancer Epidemiol Biomarkers Prev. 2005; $14: 1847-50$ 